\title{
Diethyl Pyrocarbonate Is an Inhibitor of Cardiac, Intestinal and Renal Ecto-ATPase
}

\author{
Teruhiko Okada, Vadim S. Zinchuk, Toshihiro Kobayashi, Eva Garcia del Saz \\ and Harumichi Seguchi
}

Department of Anatomy and Cell Biology, Kochi Medical School, Nankoku, Kochi 783-8505

Received for publication November 29, 1997 and in revised form January 19, 1998

\begin{abstract}
The inhibitory effect of diethyl pyrocarbonate (DEPC) on ecto-ATPase activity was evaluated in the rat cardiac muscle, small intestine and kidney using correlated biochemical and histocytochemical methodologies. The activity of the enzyme decreased in nonlinear proportion in correlation with increase of concentrations of DEPC. Essentially all ecto-ATPase activity was abolished in

response to $1.0 \mathrm{mM}$ DEPC in biochemical assays. No reaction product was detected using both confocal and electron microscopy when the tissues were pre-incubated with $1.0 \mathrm{mM}$ DEPC. The present results show that DEPC can be reliably applied to substantiate the specificity of the demonstration of ecto-ATPase activity both biochemically and histocytochemically.
\end{abstract}

Key words: Ecto-ATPase, Diethyl pyrocarbonate, Enzyme cytochemistry, Confocal microscopy

\section{Introduction}

Ecto-ATPases are multifunctional enzymes of cell membranes. These enzymes are involved in the regulation of extracellular concentrations of nucleotides and in the modulation of biological responses of tissues to changes in these concentrations [2, 14]. Ecto-ATPases rapidly hydrolyze nucleotide tri- and/or diphosphates, can be stimulated with an increase of $\mathrm{Ca}$ and $\mathrm{Mg}$ ions to a similar extent, and are insensitive to specific inhibitors of P-type, V-type and F-type ATPases [15]. However, the exact functions of ecto-ATPases are not elucidated fully. It was postulated that in mammalian cardiac muscle ecto-ATPase participates in both signal transduction and adenosine recycling [10]. Intestinal ecto-ATPase presumably functions as a bile acid-binding protein [6]. In kidney, the enzyme is involved in the regulation of cell-cell interactions at the level of microvilli of proximal convoluted tubules mediated by ATP/ADP [17]. It was recently found that amino acid sequence of ecto-ATPase is significantly homologous to human CD39, B-cell activation marker, suggesting that the enzyme is also related to immune responses [20].

Thorough understanding of physiological functions

Correspondence to: Dr. Harumichi Seguchi, Department of Anatomy and Cell Biology, Kochi Medical School, Kohasu, Okohcho, Nankoku, Kochi 783-8505, Japan. of the enzyme was hampered by the absence of efficient specific inhibitors, since several phosphatases are capable of cleaving ATP and eventually mask ecto-ATPase activity [3] and furthermore, ecto-ATPase, a very active enzyme, may contribute to other ATP-hydrolyzing enzymes, such as Na-K-ATPase and Ca-ATPase, as well.

Recently, diethyl pyrocarbonate (DEPC) was introduced as an inhibitor of extracellularly-oriented $\mathrm{Mg}$ ATPase of chicken and rabbit skeletal muscle [18]. As was shown previously cytochemically, DEPC inhibits ectoATPase activity in rat kidney, heart, liver and cerebellum [13] and in human neutrophils [8]. The use of correlated biochemical and histocytochemical experiments, however, may deepen the understanding of physiological functions of the enzyme, provide a better opportunity to study the effects of various chemicals and substantiate the use of them. Therefore, in the present study we attempted to evaluate the efficiency of the inhibition of ecto-ATPase activity by DEPC in rat cardiac muscle, intestine and kidney, using both biochemical and histocytochemical approaches.

\section{Materials and Methods}

\section{Chemicals}

Adenosine 5'-triphosphate (ATP) (disodium salt), levamisole, diethyl pyrocarbonate (DEPC), Triton X-100 and ATP reagent kit 366-A were purchased from Sigma Chemical (St. Louis, Mo, USA). Tris (hydroxymethyl) 
aminomethane), maleic acid and cerium chloride were from Nacalai Tesque Inc. (Kyoto, Japan). All the chemicals used were of analytical grade.

\section{Animals}

20 male Sprague-Dawley rats weighing 200-250 g were used. The animals were perfused through the left ventricle of the heart with an ice-cold mixture of $2 \%$ paraformaldehyde and $2 \%$ glutaraldehyde (GLA) in $0.1 \mathrm{M}$ cacodylate buffer, $\mathrm{pH} 7.2$, containing $5 \%$ sucrose. After perfusion for $15 \mathrm{~min}$, the left ventricle of the heart, intestine (duodenum and ileum) and kidney were removed from the donor animals and cut into pieces less than $1 \mathrm{~mm}$ in thickness and fixed further with the same fixative for $1 \mathrm{hr}$ at $0-4^{\circ} \mathrm{C}$. Then, the tissues were sliced into sheets of a thickness of $10-40 \mu \mathrm{m}$ for histochemical and into those of $40 \mu \mathrm{m}$ for cytochemical assays with a Microslicer (DTK3000, Dosaka EM, Kyoto, Japan), washed overnight with $0.1 \mathrm{M}$ cacodylate buffer, $\mathrm{pH} 7.2$, rinsed briefly with $0.1 \mathrm{M}$ Tris-maleate buffer, $\mathrm{pH} 7.2$, and employed for each assay.

\section{Biochemical assays}

Tissue slices of $20 \mathrm{mg}$ total wet weight were incubated in $10 \mathrm{ml}$ reaction medium containing $0.1 \mathrm{M}$ Tris-maleate buffer, pH 7.2, $2 \mathrm{mM} \mathrm{ATP,} 2 \mathrm{mM} \mathrm{MgCl}_{2}, 20 \mathrm{mM} \mathrm{KCl}$, and $2 \mathrm{mM}$ levamisole. Incubation of the tissue specimens lasted for $30 \mathrm{~min}$ at $37^{\circ} \mathrm{C}$. After incubation, reaction was terminated, the specimens were removed, and the medium was subjected to biochemical analysis. ATP was quantified by determining the decrease in absorbance that is noticed when NADH is oxidized to NAD using the procedure described by Bücher (1947) as modified by Adam (1963). The decrease in absorbance was measured at $340 \mathrm{~nm}$ in a Hitachi 220A spectrophotometer (Hitachi Ltd., Tokyo, Japan). Hydrolyzed ATP in a medium after incubation of the tissue slices was utilized to quantify ecto-ATPase activity. The maximum rate of hydrolysis was equated to $100 \%$ of the enzyme activity. Control measurements without tissues were routinely performed as well.

\section{Histocytochemical assays}

Tissue slices with a thickness of $40 \mu \mathrm{m}$ were incubated in a medium under the conditions of a biochemically defined optimum described above with the addition of $2 \mathrm{mM}$ $\mathrm{CeCl}_{3}$ to visualize the cytochemical reaction product and of $0.0002 \%$ Triton X-100 to enhance the penetration of components of the reaction medium into the incubated

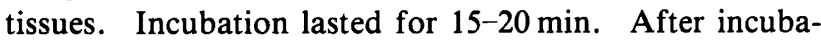
tion, the tissue slices were rinsed briefly with $0.1 \mathrm{M}$ Trismaleate buffer, $\mathrm{pH}$ 6.0.

\section{Confocal laser scanning microscopy}

Tissue slices with a thickness of $10-20 \mu \mathrm{m}$ were placed on slide glasses, coverglassed, and processed for confocal scanning using LSM 410 (Carl Zeiss, Jena, Germany) laser scanning microscope operated in a reflectance mode with the excitation of internal helium-neon laser in the wave length of $543 \mathrm{~nm}$. The system was set up from an Axiovert 135 M (Carl Zeiss, Oberkochen, Germany) microscope. Digital images were stored on MO disk and further processed using Macintosh 9600 Power PC (Apple Computer, Cupertino, CA, USA) with Adobe Photoshop software (Adobe Systems, Mountain View, CA, USA).

\section{Electron microscopy}

The tissues were then postfixed in $0.1 \mathrm{M}$ cacodylatebuffered $1 \% \mathrm{OsO}_{4}, \mathrm{pH} 7.4$, dehydrated in a graded series of ethanol, and embedded in Spurr's epoxy resin. Ultrathin sections were stained with uranyl acetate and lead citrate and then examined in Hitachi H-700 (Hitachi Ltd., Tokyo, Japan) and JEM 100S (JEOL Ltd., Tokyo, Japan) electron microscopes at accelerating voltages of 75 $\mathrm{kV}$ and $80 \mathrm{kV}$, respectively.

\section{Effect of DEPC}

The inhibitory effect of DEPC was tested in the chemical concentrations ranging from 0.1 to $1.0 \mathrm{mM}$. It was applied in ethanol-dissolved form. Solutions of the chemical were prepared prior to use. Tissue slices were pre-incubated with DEPC in $0.1 \mathrm{M}$ Tris-maleate buffer, $\mathrm{pH} 7.2$, for $10 \mathrm{~min}$ at $0-4^{\circ} \mathrm{C}$.

\section{Results}

\section{Estimation of the biochemical inhibition}

When DEPC was added, any turbidity of the biochemical medium did not appear even after the latter was kept for several hours. Addition of the chemical

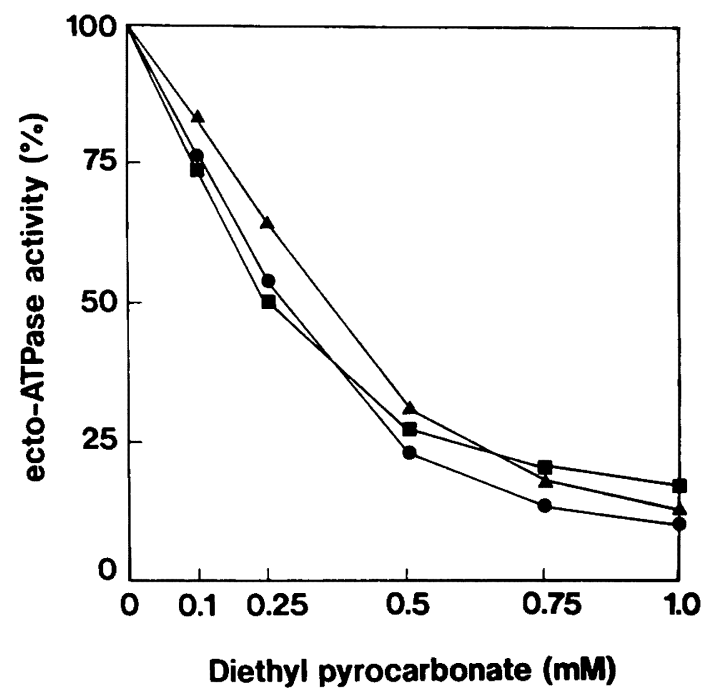

Fig. 1. Correlations of the inhibition of ecto-ATPase activity in response to increase in concentrations of DEPC in cardiac muscle (triangles), intestine (squares), and kidney (circles). Biochemical assays. Ecto-ATPase activity decreases together with increase in the concentration of DEPC. Note a common profile of the inhibition in the three tissues. The symbols represent mean values of the measurements in four independent experiments. 

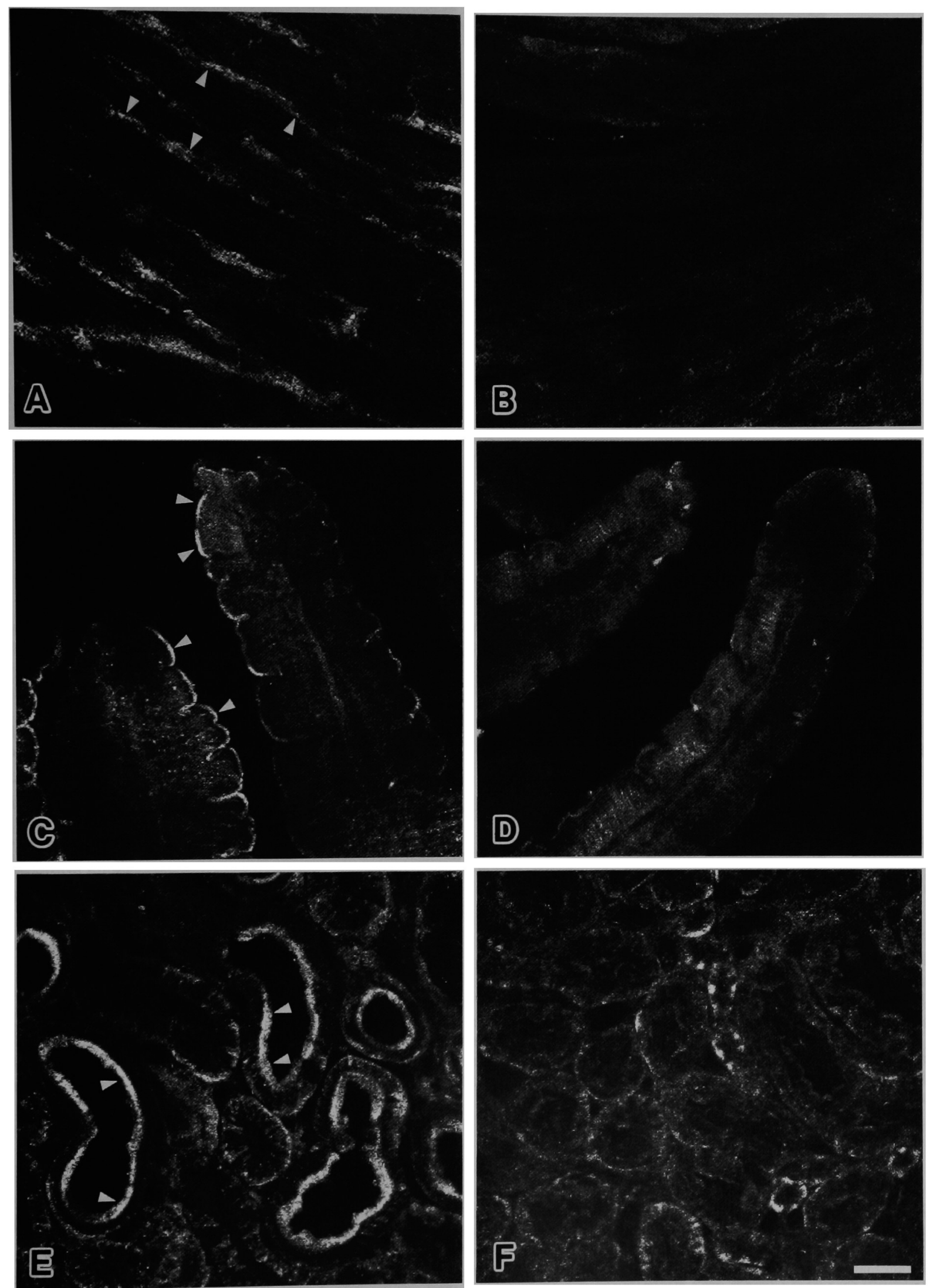

Fig. 2 

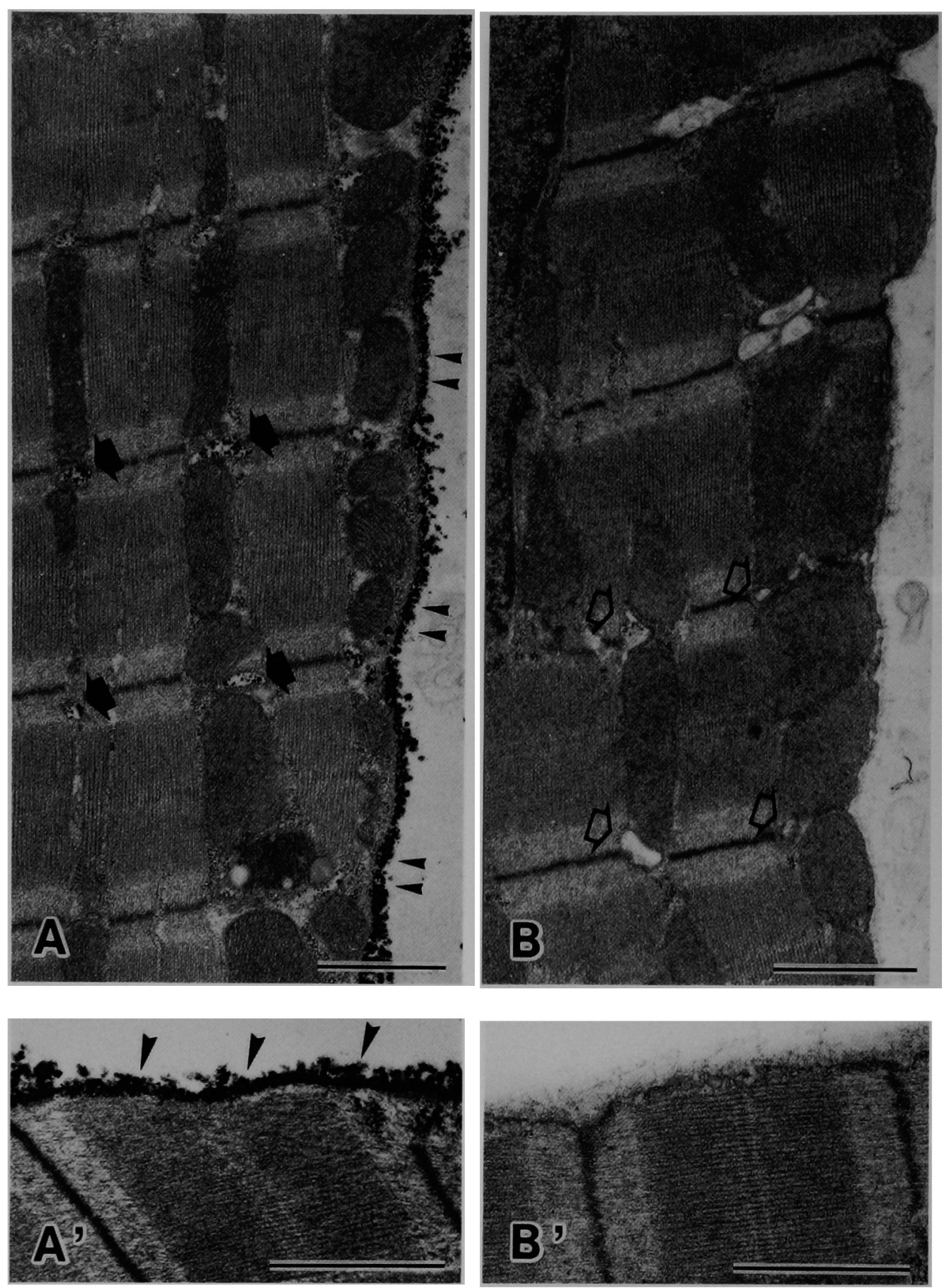

Fig. 3. Inhibitory effects of DEPC on ecto-ATPase activity in cardiac muscle. Cytochemical localization. RP is visualized at the plasma membrane of the cardiac myocytes (arrowheads) and at the T-tubules (filled arrows), when the tissue was incubated in a full reaction medium. (A). No RP is obtained after pre-incubation with $1.0 \mathrm{mM} \mathrm{DEPC} \mathrm{(B).} \mathrm{Open} \mathrm{arrows} \mathrm{point} \mathrm{to} \mathrm{the} \mathrm{absence} \mathrm{of} \mathrm{RP} \mathrm{at} \mathrm{the} \mathrm{T-tubules.} \mathrm{Higher} \mathrm{magnifica-}$ tion of the myocyte plasma membrane shows RP exclusively on its outer surface (arrowheads) after incubation in a full reaction medium (A') and complete absence of the RP in controls with DEPC (B'). Bars: $1 \mu \mathrm{m}$.

Fig. 2. Inhibitory effects of DEPC on ecto-ATPase activity. Confocal reflectance images of the cardiac muscle (A, B), intestine (C, D), and kidney (E, F) after incubation in a full reaction medium and pre-incubation with $1.0 \mathrm{mM}$ DEPC. A: reflectant material is visualized at the plasma membrane of cardiac myocytes (arrowheads). No specific reflectance is detected after pre-incubation with $1.0 \mathrm{mM} \mathrm{DEPC} \mathrm{(B).} \mathrm{C:}$ reflectant material is found at the brush border of villi of intestinal absorptive cells (arrowheads). No specific reflectance is revealed after preincubation with $1.0 \mathrm{mM} \mathrm{DEPC} \mathrm{(D).} \mathrm{E:} \mathrm{reflectant} \mathrm{material} \mathrm{is} \mathrm{noted} \mathrm{at} \mathrm{the} \mathrm{brush} \mathrm{border} \mathrm{of} \mathrm{renal} \mathrm{proximal} \mathrm{convoluted} \mathrm{tubules} \mathrm{(arrowheads).}$ Specific reflectance is hardly detected after pre-incubation with $1.0 \mathrm{mM}$ DEPC (F). Bar: $10 \mu \mathrm{m}$. 

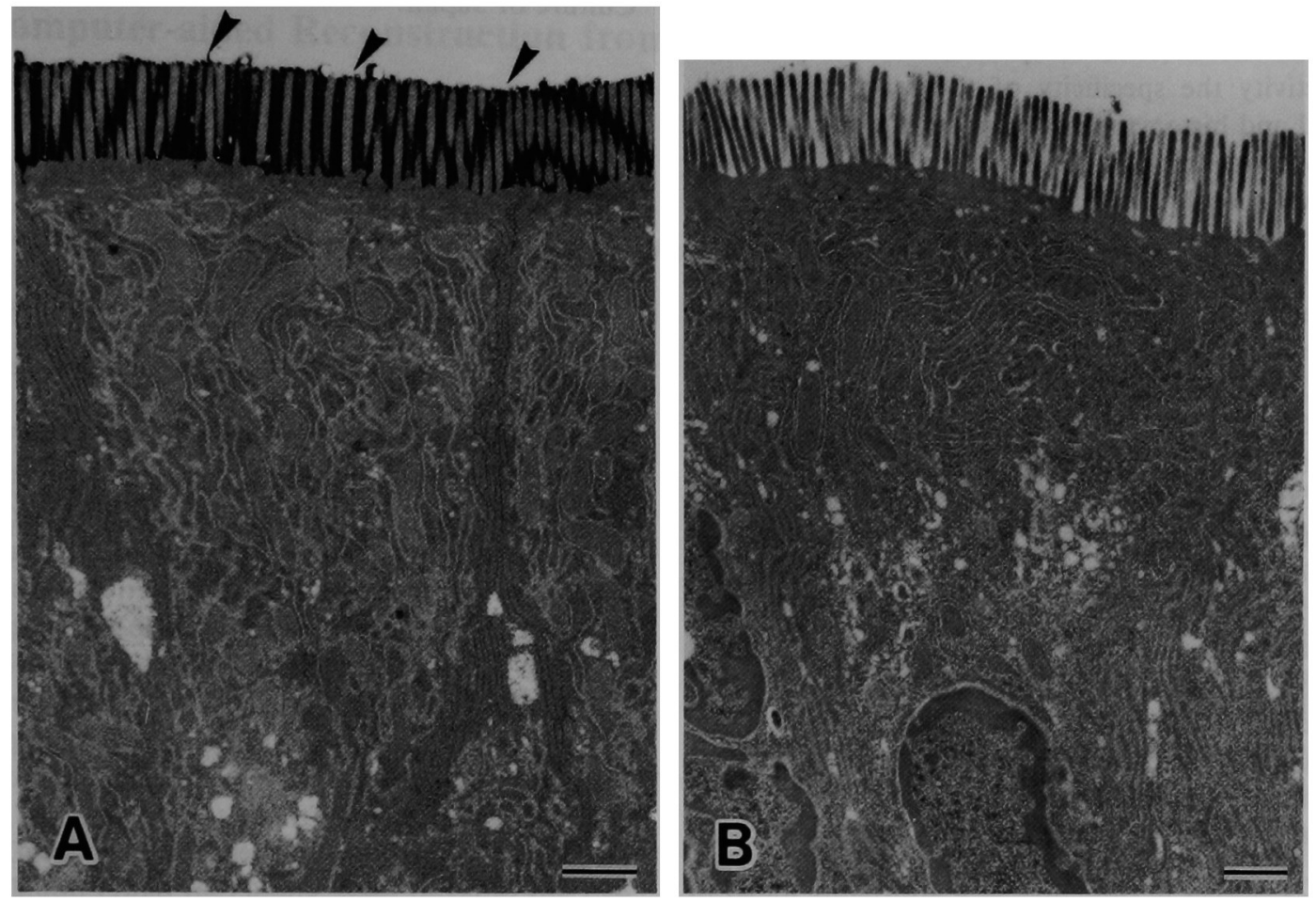

Fig. 4. Inhibitory effects of DEPC on ecto-ATPase activity in small intestine. Cytochemical localization. RP is detected at the brush border of intestinal villous absorptive cell (arrowheads), if tissue was incubated in a full reaction medium (A). In contrast, no RP is visualized after pre-incubation with $1.0 \mathrm{mM}$ DEPC (B). Bars: $1 \mu \mathrm{m}$.

resulted in immediate and dramatical decreases of ectoATPase activity in all the tissues examined. Only $51 \%$ of ecto-ATPase activity in intestine, $54 \%$ in kidney, and $64 \%$ in cardiac muscle survived in response to $0.25 \mathrm{mM}$ DEPC. At $1.0 \mathrm{mM}$ DEPC, residual enzyme activities constituted $10 \%, 14 \%$, and $8 \%$ compared to the activity in a full reaction medium when DEPC was not employed $(100 \%)$ in the cardiac muscle, intestine and kidney, respectively.

\section{Estimation of the histocytochemical inhibition}

Addition of DEPC to the histocytochemical medium resulted in a slightly opalescent coloration. To keep the medium transparent, tissue slices were needed to be preincubated with DEPC in 0.1 M Tris-maleate buffer, $\mathrm{pH} 7.2$, for $10 \mathrm{~min}$ at $0-4^{\circ} \mathrm{C}$ prior to incubation in a full reaction medium.

\section{Light microscopy}

Confocal laser scanning microscopy (CLSM), when operated in a reflectance mode, has been shown to be very useful for direct visualization of a cerium-based reaction product (RP), which is sufficiently reflective [16]. The CLSM was employed to examine a cerium-based RP, after incubation of tissues in the full reaction medium, biochemically established as optimum, and after preincubation with 1.0 mM DEPC. After incubation in a full medium, specific reflectance was detected at the plasma membrane of cardiac myocytes (Fig. 2A), at the brush border of villi of intestinal absorptive cells (Fig. 2C), and at the brush border of renal proximal convoluted tubules (Fig. 2E). No reflectance was detected in the three histologic sites after pre-incubation with $1.0 \mathrm{mM}$ DEPC (Fig. 2B, D, F).

\section{Electron microscopy}

Electron microscopic observations were in agreement with the results obtained using CLSM. RP was obtained exclusively at the extracellular surfaces of the plasma membrane of cardiac myocytes (Fig. 3A, A') and the plasma membrane of microvilli of striated brush border of intestinal absorptive cells (Fig. 4A). Virtually no RP was cytochemically visualized after pre-incubation with 1.0 mM DEPC in all the cytologic sites studied (Figs. 3B, 3B', 4B).

\section{Discussion}

It is commonly accepted that the use of inhibitors for controls of the specificity of enzymatic reactions is crucial for the reliable interpretation of both biochemical and histocytochemical data [3]. If any specific inhibitor has not yet been found or was not applied in the course of 
studies, the results obtained are of little value. This is in particular the case when using ATP as a substrate, since it is an ubiquitous molecule, which can be splitted by several enzymes. In the absence of specific inhibitor of ectoATPase activity the specificity of the reaction in both biochemical and histocytochemical studies was confirmed indirectly by revealing that the enzyme is insensitive to the other known specific inhibitors of P-type (ouabain and sodium orthovanadate), $\mathrm{V}$-type ( $\mathrm{N}$-ethylmaleimide) and $\mathrm{F}$ type (azide) ATPases [3, 20]. However, the use of specific inhibitor has an obvious advantage to confirm the specificity of the reaction directly. In the present study we show that DEPC is a very efficient inhibitor of ecto-ATPase activity. Our results are substantiated by the use of correlated biochemical and histocytochemical assays.

DEPC $\left(\mathrm{C}_{6} \mathrm{H}_{10} \mathrm{O}_{5}\right.$, ethoxyloformic anhydride), molecular weight 162.1, was initially employed as a nuclease inhibitor for preparation of RNA [9]. Subsequently, Tenu et al. (1976) reported a high degree of selectivity of this reagent to histidyl residues of Ca-stimulated ATPase. Under the conditions of the present experiment, strong inhibitory effect of DEPC was obtained both biochemically and histocytochemically. In the biochemical experiments, the activity of the enzyme dramatically declined in response to the increase in concentrations of DEPC. Any residual activity was undetectable using either CLSM or electron microscopy. It is to be mentioned that the decrease in the activity in the cardiac muscle, intestine and kidney was remarkably similar in profile biochemically, suggesting a common mechanism underlying the inhibition. The mechanism of the inhibition presumably involves the binding of the chemical to histidyl residues of ecto-ATPase at neutral $\mathrm{pH}$ of the media [5], although in alkaline media DEPC can react with lysine, tyrosine and cysteine residues as well. However, only at neutral $\mathrm{pH}$ can the inhibition be reversed by hydroxylamine $[7,11]$. At this $\mathrm{pH}$, the reaction of DEPC with proteins has been demonstrated as highly specific to histidyl residues [12], and the inhibition of the enzyme was proved as very efficient [18]. Since we employed a reaction medium with a neutral $\mathrm{pH}$, it is likely that in all tissues tested under conditions of the present experiment activity of ecto-ATPase was inhibited by binding of DEPC to histidyl residues of the enzyme.

In conclusion, the inhibitory effect of DEPC on ectoATPase activity in the rat cardiac muscle, intestine and kidney was studied using correlated biochemical and histocytochemical methodologies. The present results reveal that in all the tissues examined DEPC ensured strong inhibition of ecto-ATPase activity both biochemically and histocytochemically. Therefore, DEPC can be valuable to study ecto-ATPase activity to ensure that no any other enzyme is implicated.

\section{Acknowledgments}

This work was supported in part by Grants-in-Aid for
Scientific Research (C) (Nos. 07807101 and 07670021) from the Ministry of Education, Science, Sports and Culture of Japan.

\section{References}

1. Adam, H.: Adenosine-5'-triphosphate determination with phosphoglycerate kinase. In "Methods of Enzymatic Analysis", ed. by H.U. Bergmeyer, Academic Press, New York, 1963, pp. 539-543.

2. Banerjee, R. K.: Ecto-ATPase. Mol. Cell. Biochem. 37; 9199, 1981.

3. Borgers, M. and Verheyen, A.: Enzyme cytochemistry. Int. Rev. Cytol. 95; 163-227, 1985.

4. Bücher, T.: Über ein phosphatübertragendes Garungsferment. Biochim. Biophys. Acta 1; 292-313, 1947.

5. Coan, C. and DiCarlo, R.: Effect of diethyl pyrocarbonate modification on the calcium binding mechanism of the sarcoplasmic reticulum ATPase. J. Biol. Chem. 265; 5376-5384, 1990.

6. Gong, Y. -Z., Kato, T., Schwartz, D. A., Norris, J.S. and Wilson, F.A.: Ontogenic and glucocorticoid-accelerated expression of rat $14 \mathrm{kDa}$ bile acid-binding protein. Anat. Rec. 245; 532-538, 1996.

7. Kirley, T. L.: Purification and characterization of $\mathrm{Mg}^{2+}$ ATPase from rabbit skeletal muscle transverse tubule. $J$. Biol. Chem. 263; 12682-12689, 1988.

8. Kobayashi, T., Okada, T., Garcia del Saz, E. and Seguchi, H.: Internalization of ecto-ATPAse activity in human neutrophils upon stimulation with phorbol ester or phormyl peptide. Histochem. Cell Biol. 107; 353-363, 1997.

9. Leonard, N. J., McDonald, J. J. and Reichmann, M. E.: Reaction of diethyl pyrocarbonate with nucleic acid components, I. Adenine. Proc. Natl. Acad. Sci. USA 67; 93-98, 1970.

10. Meghij, P., Pearson, J. D. and Slakey, L. L.: Regulation of extracellular adenosine production by ectonucleotidases of adult rat ventricular myocyes. Am. J. Physiol. 32; H40-H47, 1992.

11. Melchior, W. B. Jr. and Fahrney, D.: Ethoxyformylation of proteins. Reaction of ethoxyformic anhydride with $\alpha$-chymotrypsin, pepsin, and pancreatic ribonuclease at pH 4. Biochemistry 9; 251-258, 1970.

12. Miles, E. W.: Modification of histidyl residues in proteins by diethyl-pyrocarbonate. Methods Enzymol. XLVII; 431-442, 1977.

13. Okada, T., Kobayashi, T., Jin, Q.S. and Seguchi, H.: Ultracytochemical localization of ecto-ATPase activity using cerium. Acta Histochem. Cytochem. 26; 471, 1993.

14. Pearson, J. D.: Ectonucleotidases. Measurement of activities and use of inhibitors. Methods Pharmacol. 6; 83-107, 1985.

15. Plesner, L.: Ecto-ATPases: identities and functions. Int. Rev. Cytol. 158; 141-214, 1995.

16. Robinson, J. M. and Batten, B. E.: Localization of ceriumbased reaction products by scanning laser reflectance confocal microscopy. J. Histochem. Cytochem. 38; 315-318, 1990.

17. Sabolic, I., Culic, O., Lin, S. -H. and Brown, D.: Localization of ecto-ATPase in rat kidney and isolated renal cortical vesicles. Am. J. Physiol. 262; F217-F228, 1992.

18. Saborido, A., Moro, G. and Megías, A.: Transverse tubule $\mathrm{Mg}^{2+}$-ATPase of skeletal muscle. J. Biol. Chem. 266; 23490-23498, 1991.

19. Tenu, J. -P., Ghelis, C., Saint Leger, D., Carrette, J. and Chevallier, J.: Mechanism of an active transport of calcium. J. Biol. Chem. 251; 4322-4329, 1976.

20. Wang, T. -F. and Guidotti, G.: CD39 is an ecto-( $\left(\mathrm{Ca}^{2+}, \mathrm{Mg}^{2+}\right)-$ apyrase. J. Biol. Chem. 271; 9898-9901, 1996. 